Review

\title{
Immunomodulation of Interleukin-34 and its Potential Significance as a Disease Biomarker and Therapeutic Target
}

\author{
Yun $\mathrm{Ge}^{1^{*}}$, Man Huang1 ${ }^{*}$, Yong-ming Yao ${ }^{1,2,3 凶}$ \\ 1. Department of General Intensive Care Unit, the Second Affiliated Hospital of Zhejiang University School of Medicine, Hangzhou 310052, China. \\ 2. Trauma Research Center, Fourth Medical Center of the Chinese PLA General Hospital, Beijing 100048, China. \\ 3. State Key Laboratory of Kidney Disease, the Chinese PLA General Hospital, Beijing 100853, People's Republic of China. \\ *Yun Ge and Man Huang have contributed equally to this work.
}

$\square$ Corresponding author: Yong-ming Yao, M.D., Ph.D., Trauma Research Center, Fourth Medical Center of the Chinese PLA General Hospital, 51 Fu-Cheng Road, Beijing 100048, China.Tel: (+86)1066867394; Fax: (+86)1068989158; E-mail: yaoyongming@301hospital.com.cn.

(c) Ivyspring International Publisher. This is an open access article distributed under the terms of the Creative Commons Attribution (CC BY-NC) license (https://creativecommons.org/licenses/by-nc/4.0/). See http://ivyspring.com/terms for full terms and conditions.

Received: 2019.03.20; Accepted: 2019.05.15; Published: 2019.07.20

\begin{abstract}
Interleukin (IL)-34 is a cytokine discovered a few years ago and identified as the second colony-stimulating factor (CSF)-1 receptor (CSF-1R) ligand. Although CSF-1 and IL-34 share the same receptor through which they trigger similar effects, IL-34 also binds to receptors protein-tyrosine phosphatase (PTP)- $\zeta$ and syndecan-1. Thus, IL-34 is involved in several signaling pathways and participates in a wide array of biological actions. This review analyzes current studies on the role of IL-34 under physiological and pathological conditions, and explores its potential significance as a disease biomarker and therapeutic target. In physiological conditions, IL-34 expression is restricted to the microglia and Langerhans cells, with a fundamental role in cellular differentiation, adhesion and migration, proliferation, metabolism, and survival. It is released in response to inflammatory stimuli, such as pathogen-associated molecular patterns or pro-inflammatory cytokines, with effects over various immune cells, including monocytes, macrophages, and regulatory $T$ cells that shape the immune microenvironment. Over the past decade, accumulating evidence has suggested a potent immune regulation of IL-34 in pathological states such as autoimmune diseases, cancer, transplant rejection, neurologic diseases, infections, and inflammatory diseases. Importantly, IL-34 may hold great promise for acting as a biomarker for monitoring disease severity and progression, and may serve as a new therapeutic target for the treatment of several diseases in clinical settings.
\end{abstract}

Key words: interleukin-34, colony-stimulating factor-1 receptor ligand, immune response, inflammation, disease

\section{Introduction}

Interleukin (IL)-34 is the second ligand of colony-stimulating factor-1 receptor (CSF-1R) to be discovered [1]. Figure 1 shows a timeline of major advances in IL-34 research. In 2002, a study of Dai et al. helped to predict a new ligand for CSF-1R. Deficiency of CSF-1R in mice contributed to a more severe decrease in macrophages and osteopetrosis phenotype compared with CSF-1-deficient mice, suggesting that CSF-1R could result from its CSF-1-independent activation [2]. In 2008, the discovery of IL-34 completed the understanding of activation of CSF-1R signaling [1]. The CSF-1/CSF-1R axis is critical for differentiation, proliferation, viability, and survival of hematopoietic cells [2-4]. As another ligand of CSF-1R, IL-34 shares functional similarity with CSF-1, acting as an important modulator of macrophage, osteoclast, and monocyte functions. At the same time, IL-34 shows differences from CSF-1 in its expression pattern, and it acts through additional signaling pathways $[5,6]$. Protein 
expression of IL-34 was especially evident in the spleen, skin, and brain. Several studies documented that IL-34 might play a crucial role in the development of the microglia and Langerhans cells as evident by a huge decline in these cells in IL-34-deficient mice $[7,8]$. Nakamichi et al. reported an interesting issue that IL-34 played a key role in maintaining the splenic reservoir of osteoclast precursors and their transfer to the bone in CSF-1-deficient mice [6]. However, IL-34 mRNA was extensively expressed in tissues and its expression could be changed in various pathological contexts [5]. For example, IL-34 expression is induced in response to pro-inflammatory cytokines, pathogenassociated molecular patterns (PAMPs), viral infection, and chemical stimuli. This process can be modulated by nuclear factor (NF)- $\mathrm{kB}$ signaling $[9,10]$. Interestingly, IL-34 secreted by regulatory $\mathrm{T}$ cells (Tregs) could mediate immune tolerance [11]. In addition, protein-tyrosine phosphatase (PTP)- $\zeta$ and syndecan-1 (CD138) were recently identified as functional receptors for IL-34. Through these receptors, IL-34 helped intracellular signaling pathways involved in migration, proliferation, motility, and clonogenicity of myeloid cells $[12,13]$.

In the current review, we recapitulate emerging knowledge with regard to receptor and signaling pathway of IL-34, its physiological significance and, in particular, its immune regulation in different diseases. Importantly, IL-34 has been proposed as a useful diagnostic and prognostic biomarker, as well as an attractive therapeutic target in various illnesses.

\section{Basic structure of IL-34}

IL-34 is a secreted homodimeric protein of 242 amino acids in humans and 235 amino acids in mouse, with a molecular mass of $39 \mathrm{kDa}$. The structure of IL-34 comprises two $\beta$ strands, four short helices, and four long helices, with an antiparallel four-helix core homologous to that of colony-stimulating factor (CSF)-1 (Figure 2) [14,15].

\section{Receptor and signaling pathway of IL-34}

CSF-1R is considered the major functional receptor of IL-34. The interaction between IL-34 and CSF-1R triggers several signaling pathways involving NF-kB, phosphoinositide 3-kinase (PI3K)/ AKT, Janus kinase (JAK), signal transducer and activator of transcription (STAT) 3, p38 mitogen-activated protein kinase (MAPK), extracellular signal-regulated protein kinases 1 and 2 (ERK1/2), and c-Jun N-terminal kinase (JNK) (Figure 3) [9,10,16-18]. IL-34 binding to CSF-1R can activate caspase- $3 / 8$ and induce autophagy via the AMP-activated protein kinase (AMPK)-UNC-51-like Kinase (ULK) 1 pathway [19].

IL-34 might signal through additional receptors, since it was strongly expressed in brain areas where CSF-1R expression was low. Mass spectrometry identified PTP- $\zeta$ as an alternative IL-34 receptor in glial cells and neuronal progenitors in the murine brain [12]. The interaction between IL-34 and PTP- $\zeta$ can induce a series of signaling cascades that inhibit motility, clonogenicity, and proliferation of specific cell types, via tyrosine phosphorylation of paxillin and focal adhesion kinase (FAK) [13]. Recently, IL-34 has been suggested to promote migration of myeloid cells in a syndecan-1-dependent manner, but the interaction of IL-34 with this receptor remains relatively unexplored.

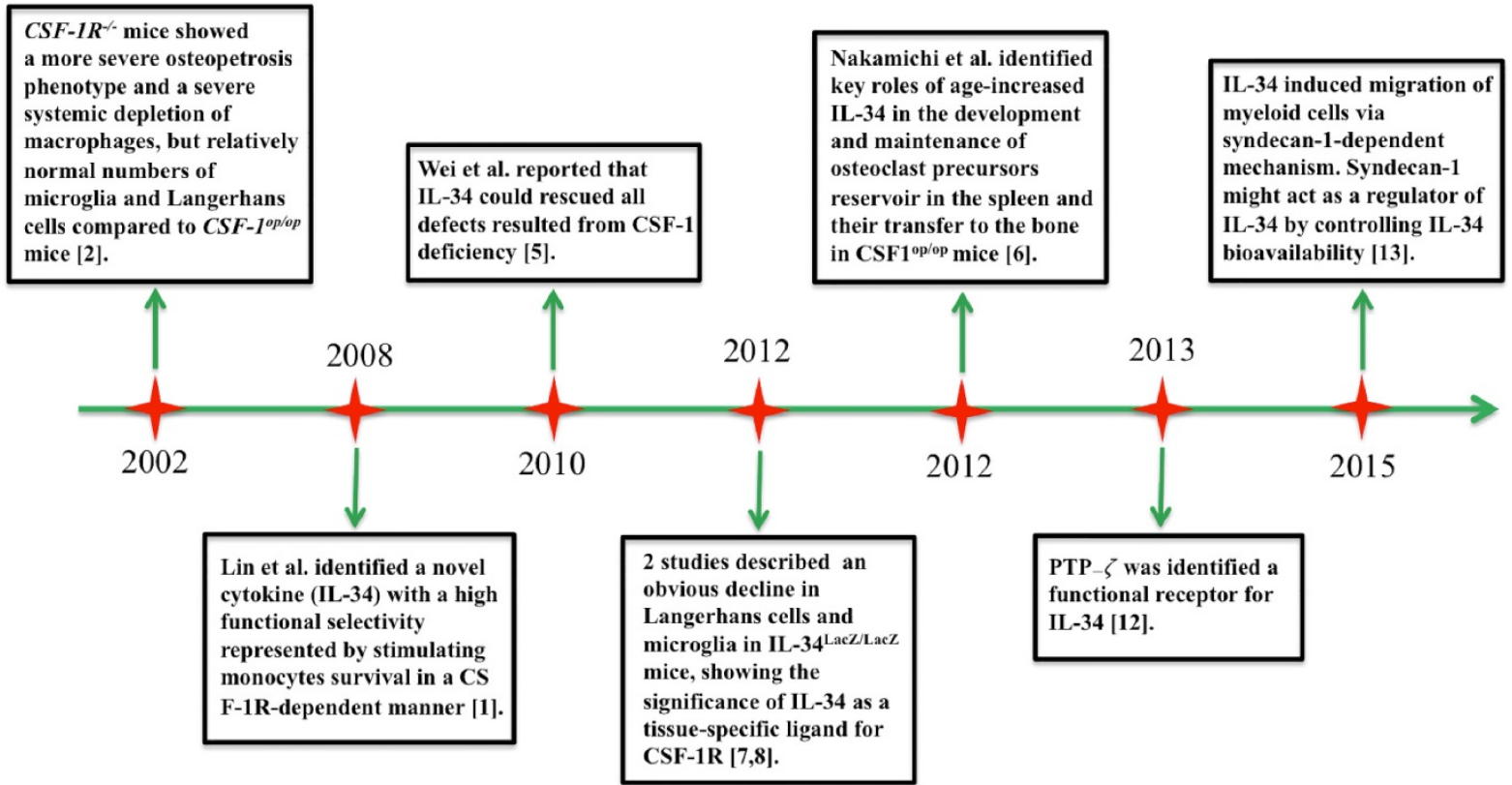

Figure 1. Timeline of major advances in IL-34 research since 2002. 


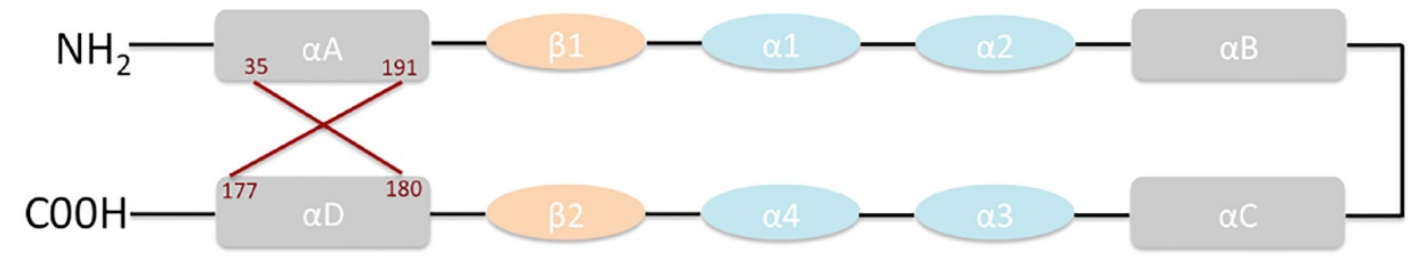

Figure 2. Structure of IL-34.

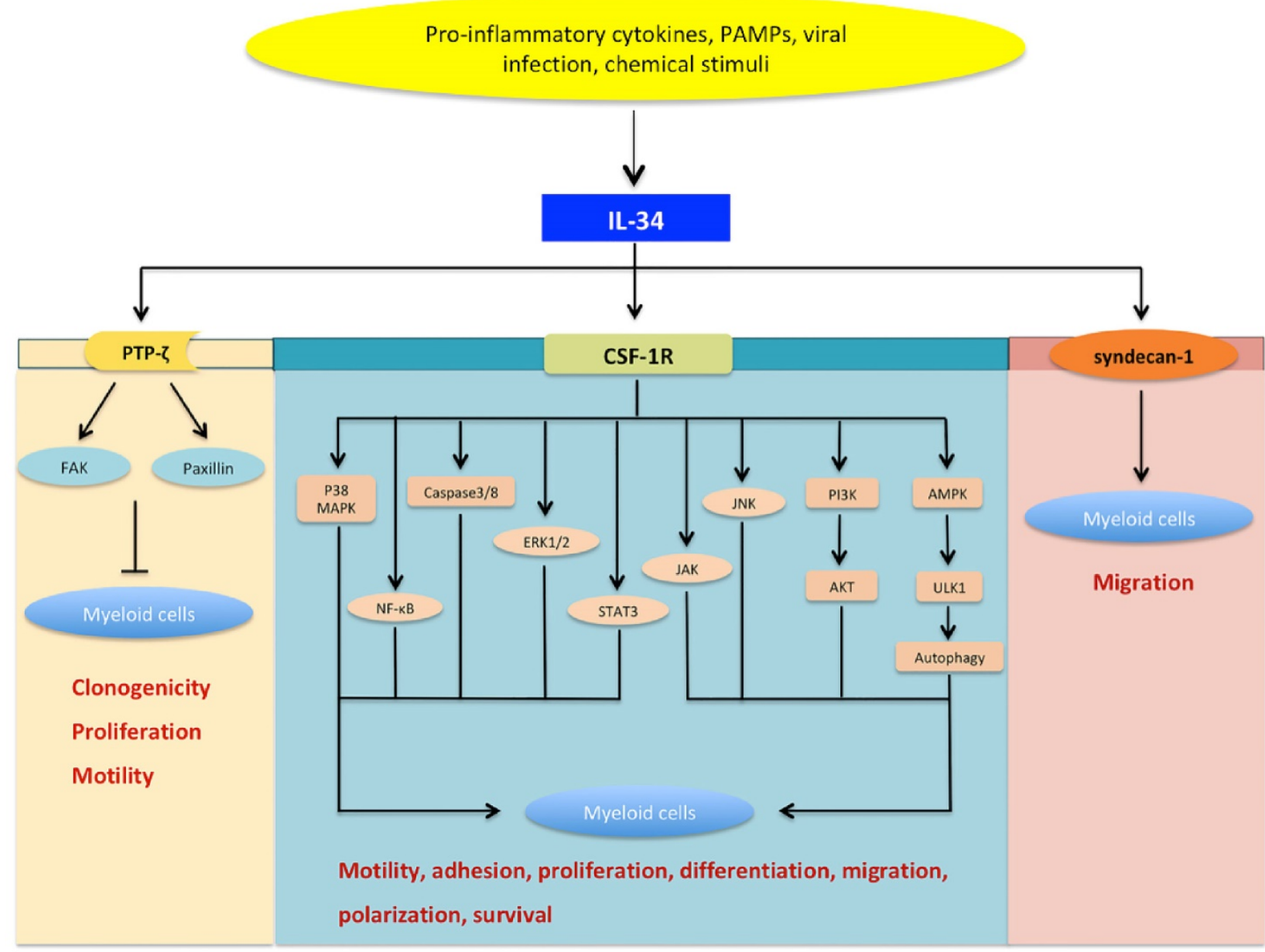

Figure 3. The signaling network of IL-34. IL-34 can be induced by various stimuli such as pro-inflammatory cytokines, pathogen-associated molecular patterns (PAMPs), viral infection, and chemical stimuli.IL-34 can bind to CSF-1 receptor (CSF-1R) and subsequently induce a series of signaling networks involving nuclear factor-kappaB (NF-KB), c-Jun N-terminal kinase (JNK), p38 mitogen-activated protein kinase (p38 MAPK), extracellular signal-regulated protein kinases 1 and 2 (ERK1/2), Janus kinase (JAK), signal transducer and activator of transcription (STAT)-3,phosphoinositide 3-kinase (PI3K)/AKT, caspase-3/8, as well as autophagy activated by AMP-activated protein kinase (AMPK)-UNC-51-like kinase (ULK) 1. Moreover, IL-34 can induce paxillin and focal adhesion kinase (FAK) by binding protein-tyrosine phosphatase $\zeta$ (PTP- $\zeta$ ). In this way, IL-34-mediated signaling is a key modulator in various cellular processes, including cellular differentiation, motility, adhesion, metabolism, proliferation, and survival. As a novel functional receptor, syndecan-1 has been shown to regulate the activation of IL-34/CSF-1R signaling and may serve as a potent regulator of IL-34 activity. Nevertheless, IL-34/syndecan-1-induced signaling is still largely unexplored.

\section{Physiological significance of IL-34}

Physiological functions of IL-34 have been indicated from many studies in animal models. For example, IL-34-deficient mice showed much lower frequencies and activities of $\mathrm{F} 4 / 80^{+} \mathrm{CD} 11 \mathrm{~b}^{+} \mathrm{CD} 45^{\text {int }}$ microglia and $\mathrm{F} 4 / 80^{+} \mathrm{CD} 11 \mathrm{~b}^{+} \mathrm{CD} 45^{+}$Langerhans cells than wild-type mice but otherwise normal fertility, lifespan, and counts of blood monocytes as well as tissue macrophages $[7,8]$. IL-34 deficiency is also linked to lower numbers of $\mathrm{CD} 11 \mathrm{c}^{+} \mathrm{CD} 11 \mathrm{~b}^{+}$dendritic cells in the lung $[7,8]$. IL-34 is selectively expressed by microglia and Langerhans cells, and it can promote the differentiation and development of these cells. Interestingly, IL-34-mediated effects appear to be restricted to physiological conditions in Langerhans cells. During inflammation, Langerhans cells rely on neutrophil-released CSF-1 other than IL-34 [19,20]; once the inflammatory response subsides, Langerhans cells are again dependent on IL-34 [21,22]. 
IL-34 plays a role in the expression pattern and the development of nervous system [23,24]. CSF-1 is constitutively expressed in the ventricular and subventricular regions of the brain, while IL-34 is restricted to the striatum and hippocampus [7]. IL-34-deficientmice showed a reduction in microglial cells in the hippocampus and cortex, confirming its role in the development and homeostasis of microglia [25]. IL-34 has been detected in the cerebrospinal fluid because of its secretion from choroid plexus and ependymal cells [8]. Taken together, these findings implicate the physiological importance of IL-34 in microglia and Langerhans cells (Figure 4). IL-34 expression is evident in the spleen, seminiferous tubule germ cells, proximal renal tubule cells, and placental syncytiotrophoblasts, while further work is needed to explore the potential function of IL-34 in these tissues [26,27].

\section{IL-34 in inflammatory and immune responses}

IL-34 can orchestrate inflammatory and immune responses, and it is markedly induced in the inflammatory milieu via signaling NF- $\mathrm{kB}$ pathways [10]. IL-34 can amplify the inflammatory effect by inducing the expression of chemokines, metalloproteases, and pro-inflammatory mediators $[28,29]$. Likewise, it has the potential to mediate the differentiation of monocytes into IL-10high IL-12 $2^{\text {low }}$ macrophages, which act as a master regulator in immune response [30]. In this context, the IL-34-differentiated macrophages are similar to tumor-associated macrophages (TAMs). IL-34-stimulated macrophages secrete membrane-associated IL-1a, which switches memory $\mathrm{T}$ cells into helper $\mathrm{T}$ cells (Th) 17 [31]. In this way, IL-34 instructs macrophages to maintain local inflammation, which is necessary for metastasis and angiogenesis. Moreover, IL-34 and CSF-1 show distinct abilities to polarize monocytes into M1 or M2 macrophages: IL-34, but not CSF-1, generates M1 and M2 macrophages that express high levels of IL-10 and chemokine ligand 17 (CCL17) [19]. IL-34-evoked macrophages can also polarize naïve $\mathrm{T}$ cells into Th1 cells [30].

While IL-34 can stimulate the immune response, it may also mediate immune tolerance and resolution of inflammation. It inhibits Toll-like receptor (TLR) signaling and production of anti-inflammatory cytokines [19,32]. IL-34-differentiated macrophages may be polarized to the M2 phenotype and exert antiinflammatory and immunosuppressive effects by suppressing the function of both $\mathrm{T}$ and natural killer (NK) cells, and expanding CD4 ${ }^{+} / \mathrm{CD}^{+}$Foxp3 ${ }^{+}$Tregs [33-35]. Therefore, IL-34 acts as a potent and pleiotropic cytokine in the regulation of inflammatory and immune processes.

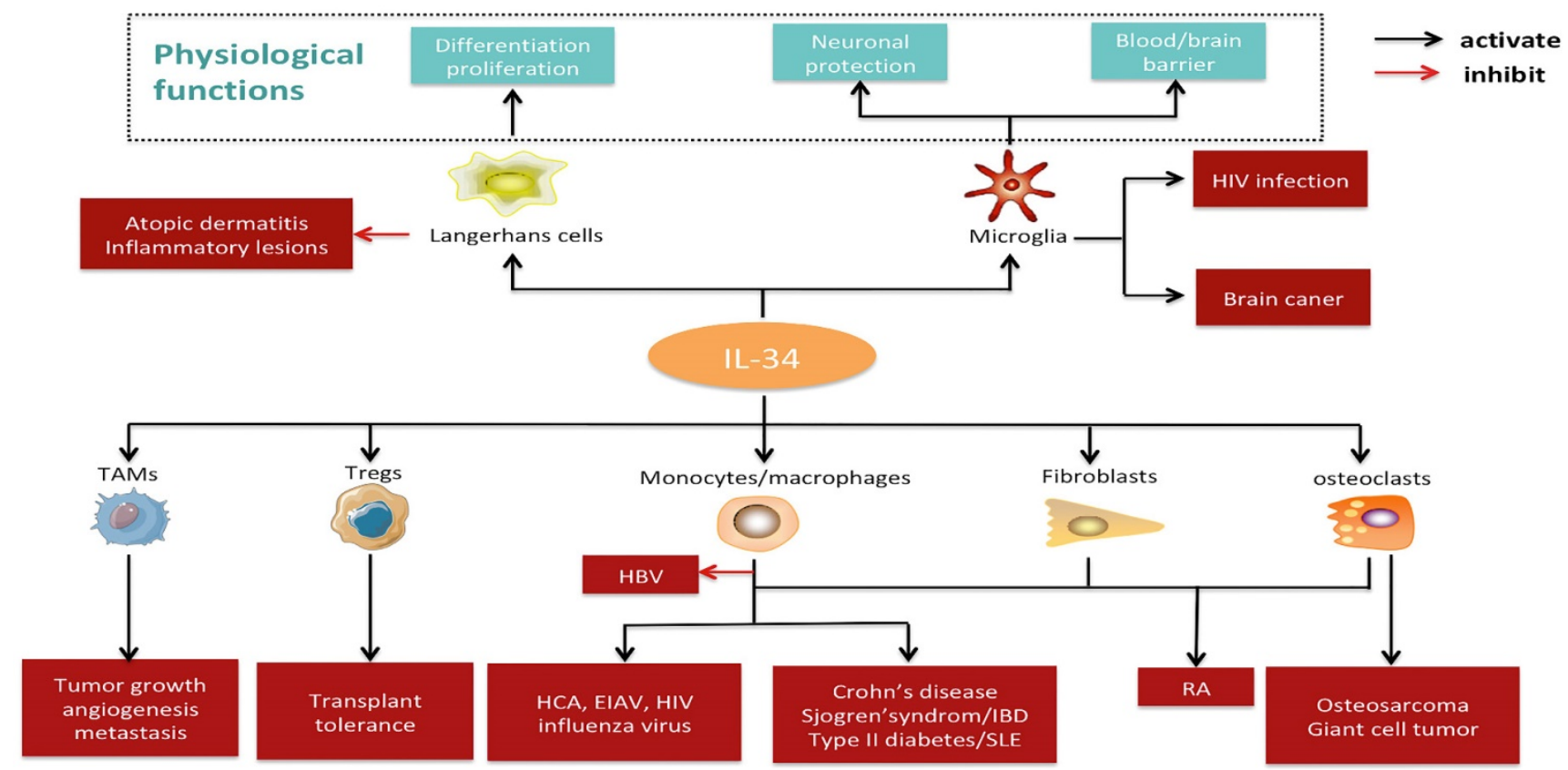

Figure 4. Pathophysiological significance and potential applications of IL-34. IL-34 is constitutively expressed in the microglia and Langerhans cells under physiological conditions, where it plays a crucial role in development, function, and survival. Under pathological states, IL-34 may exert an effect on several cell types (e.g., monocytes/macrophages, tumor-associated macrophages, regulatory T cells, fibroblasts, and osteoclasts) and contribute to the pathogenesis of various diseases, including autoimmune diseases, cancer, transplant rejection, neurologic diseases, inflammatory diseases, and infections. Abbreviations: IL-34, interleukin-34; TAMs, tumor-associated macrophages; Tregs, regulatory T cells; HBV, hepatitis B virus; HCV, hepatitis C virus; HIV, human immunodeficiency virus; EIAV, equine infectious anemia virus; IBD, inflammatory bowel disease; RA, rheumatoid arthritis; SLE, systemic lupus erythematosus; RA, rheumatoid arthritis. 


\section{Immune regulatory of IL-34 in various diseases}

There is a growing body of evidence showing that IL-34-mediated immune response participates in various pathological states (summarized in Table 1). In fact, high levels of IL-34 have been observed in animal models and patients with autoimmune diseases, cancer, transplant rejection, neurologic diseases, infections, and inflammatory disorders. Furthermore, increased levels of IL-34 are closely associated with the pathogenesis, progression, and severity of these diseases. In some cases, IL-34 levels return to the physiological range after successful treatment. Thus, IL-34 may be a promising clinical biomarker for prediction, diagnosis, and responsiveness to treatment (summarized in Table 2).

Table 1. Summary of studies concerning the clinical significance of IL-34 in different diseases.

\begin{tabular}{|c|c|c|c|c|}
\hline Diseases & Years & Authors & Clinical observations & Ref. \\
\hline \multirow[t]{9}{*}{ RA } & 2013 & Tian et al. & $\begin{array}{l}\text { Elevated serum and synovial fluid levels of IL- } 34 \text { were correlated with disease activity in RA patients. } \\
\text { The level of serum IL-34 decreased after anti-TNF treatment. }\end{array}$ & [38] \\
\hline & 2017 & Wang et al. & $\begin{array}{l}\text { Serum IL-34 levels were increased and closely related to the diseases activity of RA. IL- } 34 \text { upregulated } \\
\text { Th17 production via increased IL- } 6 \text { expression by rheumatoid fibroblast-like synoviocytes. }\end{array}$ & [39] \\
\hline & 2012 & Chemel et al. & IL-34 expression was associated with synovitis severity in RA patients. & [42] \\
\hline & 2012 & Hwang et al. & $\begin{array}{l}\text { IL-34 produced by human fibroblast-like synovial cells in RA supports osteoclastogenesis. IL-34 } \\
\text { elevation in plasma from RA patients was decreased after the administration of disease-modifying } \\
\text { anti-rheumatic drugs. }\end{array}$ & [43] \\
\hline & 2013 & Moon et al. & $\begin{array}{l}\text { Increased levels of IL-34 in serum and synovial fluid were associated with rheumatoid factor and } \\
\text { anticycliccitrullinated peptide antibody titers in patients of RA. }\end{array}$ & [44] \\
\hline & 2015 & Chang et al. & Baseline serum IL-34 levels independently predict radiographic progression in patients with RA. & [45] \\
\hline & 2016 & Garcia et al. & CSF-1R blockade reduced inflammation in human and murine models of RA. & [46] \\
\hline & 2016 & Yang et al. & $\begin{array}{l}\text { IL-34 upregulation contributed to the increment of microRNA } 21 \text { expression via STAT3 activation } \\
\text { associated with disease activity in RA. }\end{array}$ & [47] \\
\hline & 2015 & Ding et al. & IL-34 levels in serum predicted response to TNF- $\alpha$ antagonist therapy. & [50] \\
\hline \multirow[t]{2}{*}{ SLE } & 2016 & Wang et al. & Serum IL-34 levels were elevated in patients with SLE. & [53] \\
\hline & 2018 & Xie et al. & Elevated serum IL-34 level in patients with SLE was associated with disease activity. & [54] \\
\hline SS & 2013 & Ciccia et al. & $\begin{array}{l}\text { IL-34 was highly expressed in ductal epithelial cells and infiltrating mononuclear cells of the inflamed } \\
\text { salivary gland, which correlated with pro-inflammatory cytokines and local expansion of } \\
\text { pro-inflammatory CD14bright CD16+ monocytes. }\end{array}$ & [55] \\
\hline \multirow[t]{9}{*}{ Cancer } & 2017 & Raggi et al. & High levels of serum IL-34 were observed in cholangiocarcinoma. & [33] \\
\hline & 2010 & $\begin{array}{l}\text { Baud'huin et } \\
\text { al. }\end{array}$ & IL-34 expression was enhanced in giant cell tumors. & [41] \\
\hline & 2016 & Zhou et al. & High levels of IL-34 were correlated with poor prognosis in hepatocellular carcinoma. & [71] \\
\hline & 2018 & Han et al. & $\begin{array}{l}\text { IL- } 34 \text { was strongly expressed in melanoma and correlated with CD163+ cell counts in } \\
\text { nivolumab-resistant metastatic melanoma. }\end{array}$ & [69] \\
\hline & 2018 & Baghdadi et al. & IL-34 levels were correlated with tumor progression in lung cancer. & [68] \\
\hline & 2015 & $\begin{array}{l}\text { Rietkötter et } \\
\text { al. }\end{array}$ & IL-34 mRNA expression was up-regulated in breast cancer and lung cancer with brain metastasis. & [64] \\
\hline & 2015 & Ségaliny et al. & Heterogeneous expression of IL-34 was evident in human osteosarcomas. & [65] \\
\hline & 2017 & Franzè et al. & Over-expression of IL-34 was present in sporadic colorectal cancer. & [67] \\
\hline & 2014 & Cioce et al. & IL-34 was produced in malignant pleural mesothelioma cells, and it induced chemoresistance. & [62] \\
\hline $\begin{array}{l}\text { Liver } \\
\text { transplantation }\end{array}$ & 2016 & $\begin{array}{l}\text { San Segundo } \\
\text { et al. }\end{array}$ & Increased levels of serum IL-34 were noticed in acute liver rejection. & [73] \\
\hline $\mathrm{AD}$ & 2017 & Walker et al. & IL-34 expression was down-regulated in the inferior temporal gyrus in patients with AD. & [79] \\
\hline \multirow[t]{2}{*}{$\begin{array}{l}\text { HBV } \\
\text { infection }\end{array}$} & 2017 & Cheng et al. & $\begin{array}{l}\text { IL-34 levels were decreased in the serum and PBMCs of patients with chronic HBV infection, and they } \\
\text { were negatively correlated with disease activity. }\end{array}$ & {$[88]$} \\
\hline & 2018 & Wang et al. & $\begin{array}{l}\text { Serum IL- } 34 \text { was elevated in HBV infection and correlated with liver inflammation and fibrosis in } \\
\text { patients with chronic HBV infection. }\end{array}$ & [81] \\
\hline $\begin{array}{l}\mathrm{HCV} \\
\text { infection }\end{array}$ & 2014 & Preisser et al. & Increased levels of serum IL-34 were correlated with advanced liver fibrosis stage. & [82] \\
\hline $\begin{array}{l}\text { Influenza A viral } \\
\text { infection }\end{array}$ & 2015 & Yu et al. & $\begin{array}{l}\text { High levels of IL-34 were observed in PBMCs and serum in response to influenza A } \\
\text { infection. }\end{array}$ & [83] \\
\hline Sepsis & 2018 & Lin et al. & Serum IL-34 levels were increased in sepsis. & [91] \\
\hline IBD & 2015 & Franzè et al & $\begin{array}{l}\text { Over-expression of IL-34 was noted in the epithelial layer and infiltrating immune cells in the inflamed } \\
\text { mucosa. }\end{array}$ & [92] \\
\hline Atopic dermatitis & 2015 & Esaki et al. & IL-34 expression was decreased in lesional epidermis. & [95] \\
\hline $\begin{array}{l}\text { Chronic apical } \\
\text { periodontitis }\end{array}$ & 2016 & Ma et al. & $\begin{array}{l}\text { IL-34 expression was evident in plasma cells, lymphocytes, and macrophages in chronic periapical } \\
\text { lesions. }\end{array}$ & [100] \\
\hline \multirow{2}{*}{$\begin{array}{l}\text { Type } 2 \text { diabetes } \\
\text { mellitus }\end{array}$} & 2011 & Below et al. & Serum IL-34 predicted the risk of vascular diabetic complications. & [102] \\
\hline & 2016 & Zorena et al. & IL-34 was located within risk loci associated with type 2 diabetes mellitus. & [103] \\
\hline Heart failure & 2016 & Fan et al. & $\begin{array}{l}\text { High levels of serum IL-34 were correlated with cardiovascular death, risk of renal dysfunction, and } \\
\text { mortality. }\end{array}$ & [99] \\
\hline
\end{tabular}

Abbreviations: IL-34, interleukin-34; RA, Rheumatoid arthritis; SLE, Systemic lupus erythematosus; SS, Sjogren's syndrome; AD, Alzheimer's disease; IBD, inflammatory bowel disease; HBV, hepatitis B virus; $\mathrm{HCV}$, Hepatitis $\mathrm{C}$ virus infection; PBMC, peripheral blood mononuclear cell; TNF-a, tumor necrosis factor-a; CSF-1R,

Colony-stimulating factor 1 receptor. 
Table 2. Summary of studies with regard to the potential targeting IL-34 in various diseases.

\begin{tabular}{|c|c|c|c|c|}
\hline Diseases & Year & Authors & Potential applications & Ref. \\
\hline SS & 2013 & Ciccia et al. & Targeting IL-34 inhibited the expansion of CD14 bright CD16+ monocytes in inflamed salivary glands. & [55] \\
\hline RA & $\begin{array}{l}2013 \\
2016 \\
2016\end{array}$ & $\begin{array}{l}\text { Bostrom et al. } \\
\text { Yang et al. } \\
\text { Zhou et al. }\end{array}$ & $\begin{array}{l}\text { Neutralizing IL-34 attenuated the inflammatory lesions, decreased pathogenic immune cell subsets, } \\
\text { sensitized synovial fibroblasts to apoptosis, and alleviated cartilage destruction as well as bone } \\
\text { erosion in rheumatoid arthritis. }\end{array}$ & $\begin{array}{l}{[36]} \\
{[47]} \\
{[48]}\end{array}$ \\
\hline IBD & 2015 & Franze et al. & $\begin{array}{l}\text { Neutralizing IL-34 mitigated the inflammatory cascade by inhibiting the production of CCL20, } \\
\text { TNF-a, and IL- } 6 \text {. }\end{array}$ & [92] \\
\hline HBV infection & 2017 & Cheng et al. & In HBV transgenic mice, IL-34 administration suppressed the replication of HBV DNA. & [88] \\
\hline HIV infection & 2010 & Chihara et al. & Blockade of IL-34 inhibited HIV replication. & [16] \\
\hline Influenza A viral infection & 2015 & Yu et al. & Neutralizing IL-34 alleviated the inflammatory response in influenza A viral infection. & [83] \\
\hline Sepsis & 2018 & Lin et al. & Treatment with IL-34 improved bacterial clearance and survival in a mouse model of sepsis. & [91] \\
\hline Atopic dermatitis & 2015 & Esaki et al. & IL-34 suppressed propagation of the inflammatory circle in active skin lesions. & [95] \\
\hline Acute kidney injury & 2015 & Baek et al. & IL-34 mediated acute kidney injury and worsened chronic kidney disease. & [97] \\
\hline
\end{tabular}

\section{IL-34 in autoimmune diseases}

Immunomodulation of IL-34 is critically involved in the etiology of autoimmune diseases, including rheumatoid arthritis (RA), systemic lupus erythematosus (SLE), Sjogren's syndrome, psoriasis, and psoriatic arthritis. RA is a systemic and chronic autoimmune disease characterized by bone destruction and progressive cartilage. In response to stimulation by inflammatory cytokines [e.g., IL-1 $\beta$, tumor necrosis factor (TNF)- $\alpha$, IL-6, IL-17], IL-34 is produced by synovial fibroblasts and released into the synovial fluid. High levels of IL-34 can be detected in the synovial fluids and serum of RA patients. IL-34 facilitates the secretion of pro-inflammatory cytokines, and amplifies the inflammatory cascades in the NF-kB- and JNK-dependent mechanisms [36,37]. Simultaneously, elevation of IL-34 positively correlates with numerous inflammatory parameters in RA, such as leukocyte count, C-reactive protein, erythrocyte sedimentation rate, pro-inflammatory cytokine levels, severity of synovitis, synovial hyperplasia disease activity score, and auto-antibody production (e.g., rheumatoid factor, anti-cyclic citrullinated peptide antibody) [42-49]. IL-34 can induce the differentiation, proliferation, and infiltration of macrophages in the inflamed synovia, which are the central immune cells in RA pathogenesis $[31,32,36]$. It also stimulates IL-17-producing Th17 cells, which are the crucial drivers of autoimmune tissue injury in RA [38-40]. Furthermore, overexpression of IL-17 is implicated in RA etiology. It activates NF-kB ligand (RANKL)-mediated osteoclastogenesis by enhancing the proliferation and adhesion of osteoclast progenitors, leading to aggravated bone erosion [41]. RA treatment with TNF-a antagonist therapy or disease-modifying antirheumatic drugs can dramatically reduce serum IL-34 levels [50,51].

SLE is characterized by formation of immune complexes and anti-nuclear antibodies as well as activation of $\mathrm{B}$ and $\mathrm{T}$ lymphocytes, resulting in multiple organ damage. Experimental data in animal models support a pathological role of IL-34 in SLE, and elevated levels of IL-34 have been observed in patients with SLE and closely correlate with clinical outcomes [52-54]. After treatment with immunosuppressive drugs or corticosteroids, IL-34 levels return to normal range. Nonetheless, the immunoregulatory mechanisms underlying IL-34 in the pathogenesis of SLE need to be investigated in future studies.

Sjogren's syndrome is a chronic inflammatory and autoimmune disorder. Infiltration of $\mathrm{T}$ and $\mathrm{B}$ cells and altered levels of pro-inflammatory mediators play essential roles in the etiology of Sjogren's syndrome. Overexpression of IL-34 was reported in inflamed salivary glands, accompanied by production of pro-inflammatory cytokines, such as IL-17, IL-1 $\beta$, and TNF-a, and pro-inflammatory CD14 ${ }^{\text {Bright }} \mathrm{CD} 16^{+}$ monocytes $[55,56]$. Thus, IL-34 may be involved in the development of salivary gland inflammation and Sjogren's syndrome. Likely, psoriasis is a chronic inflammatory and autoimmune disease, which is frequently accompanied by psoriatic arthritis. Inflammatory mediators including IL-12, IL-1 $\beta$, and TNF- $\alpha$ were participated in the immunopathogenicity of psoriasis and psoriatic arthritis [57]. Patients with these disorders showed increased levels of serum IL-34. Clearly, psoriatic arthritis is characterized by progressive osteoclastogenesis, joint damage, and bone erosions. A strong increase in circulating IL-34 positively correlates with serum osteoclast precursors, pointing towards IL-34 as a potential clinical marker for monitoring the progression of psoriatic arthritis [57]. These findings suggest a critical role for IL-34 in the pathology of psoriasis and psoriatic arthritis.

\section{IL-34 in cancer}

TAMs act as key immune regulators in the tumor microenvironment, promoting the growth, angiogenesis, metastasis, and invasion of cancer cells, and weakening anti-tumor immunity. Clinical studies 
demonstrate a strong link between expansion of TAMs and poor outcomes in patients with cancers [58]. Thus, the size of the TAM population may serve as a clinical marker for stratifying the risk of tumors.

CSF-1R signaling is required for the function and survival of TAMs [59-61]. As a ligand of CSF-1R, IL-34 exhibits pro-tumorigenic effects and has gained attention for its potential utility in the diagnosis, prediction, and targeted therapy of cancers $[62,63]$. IL-34 recruits TAMs, which drive neo-angiogenesis and metastasis in cancers [33,34]. IL-34/CSF-1R signaling contributes to extravasation of immune cells and formation of new vessels in a paracrine manner [62-70]. IL-34 activates AKT and then triggers C/EBP $\beta$ signaling, thereby augmenting the immunosuppressive activity of TAMs in the tumor microenvironment [22,34]. In hepatocellular carcinoma, TAMs release transforming growth factor (TGF) $\beta$ and subsequently accelerate the production of IL-34, a feedback loop that is involved in metastasis [71]. Consistent with a pro-tumorigenic role of IL-34, many studies have been confirmed that the functional receptors of IL-34, including CSF-1R, PTP- $\zeta$, and syndecan- 1 , are obviously expressed in a variety of cancers $[12,13,59]$.

IL-34/CSF-1R axis can trigger survival pathways in an autocrine manner when tumor cells are treated with chemotherapy, and chemotherapy per se induces high expression of IL-34 [60]. Blockade of IL-34 or CSF-1R can improve the survival of mice with breast cancer by reducing vessel density, inhibiting proliferation of cancer cells, and enhancing $\mathrm{CD}^{+}$cellmediated anti-tumor immunity [57,58,62]. Paradoxically, IL-34 may exert antitumor effects in several cancer types. For instance, it markedly suppresses the motility, clonogenicity, and proliferation of glioblastoma cells [12,13]. Consistently, low IL-34 levels are associated with poor outcomes in various cancers $[12,13]$. Therefore, immunomodulation of IL-34 in tumors is complex, and possibly context-dependent, and should be investigated in further studies.

\section{IL-34 in transplant rejection}

Immune rejection is the major cause of transplant failure, thus induction of immune tolerance is key to successful outcomes after transplantation. IL-34 may be of importance for mediating such immune tolerance and ensuring graft survival. In a study of cardiac allografts in animal models, IL-34 induced the expansion and potentiation of $\mathrm{CD}^{+} /$ CD4 ${ }^{+}$Tregs, and protected against allograft rejection via a M2 macrophage-dependent pathway [72]. Interestingly, Tregs can release IL-34 in an autocrine manner. In a rat model of liver transplantation, IL-34 contributed to polarizing Kupffer cells to the M2 type, improving recipient survival [73]. In clinical settings, it was reported that patients who suffered acute rejection of liver or kidney transplants showed increased serum IL-34 levels and worse prognosis than those who did not experience rejection [72,73]. These results indicate that IL-34 appears to be a critical mediator of transplant tolerance and may be useful as a prognostic biomarker of graft survival.

\section{IL-34 in neurological diseases}

IL-34 has been suggested to exert immune protective effects on the central nervous system by impacting microglia, neurons, and endothelial cells. In physiological conditions, IL-34 expression is restricted to neurons, where it plays a role in maintenance of the immune homeostasis in the central nervous system [74]. In the development of diseases, IL-34 production triggers survival signaling in damaged neurons [75-77], and treatment with IL-34 markedly attenuates excitotoxin-induced neuronal loss in mice [77]. Similarly, IL-34 accelerates the degradation of oligomeric amyloid as well as the production of TGF- $\beta$ and heme oxygenase- 1 , alleviating oxidative stress [78]. In a mouse model of Alzheimer's disease, IL-34 administration significantly enhanced the clearance of soluble oligomeric amyloid- $\beta$ and improved associative learning [79]. IL-34 has the potential to up-regulate tight junction molecules to maintain the integrity of the blood-brain barrier [80]. These observations support the notions that IL-34 may exert beneficial effects against neurodegeneration and brain injury, making it a possible new therapeutic approach for the management of neurological diseases.

\section{IL-34 in infections}

It is well known that cytokines regulate host immune response during infection. Pro-inflammatory cytokines and PAMPs induce IL-34 expression, which then modulates innate immune responses to infections. IL-34 contributes to the persistence of viruses by involving in immune tolerance [20-22]. In hepatitis C infection, IL-34 is generated by hepatocytes and induces monocytes to progress to macrophages with a profibrotic phenotype, thereby facilitating the progression of hepatic fibrosis [81]. Patients with hepatitis $C$ infection reveal increased levels of IL-34 [82]; the same has been observed in patients with influenza A infection, in whom IL-34 production depends strongly on IL-22-mediated inflammatory response [83]. Notably, expression of IL-34 can be induced in macrophages infected with equine infectious anemia virus, and the cytokine promotes the proliferation of monocytes/macrophages [84]. IL-34 maybe closely associated with the survival of human immunodeficiency virus (HIV) in 
infected microglia and macrophages by inhibiting apoptosis, thereby contributing to HIV-induced neuropathogenesis [85-87]. Consistently, IL-34-stimulated macrophages show high replication of HIV. These evidences indicate that IL-34 may help to provide a favorable microenvironment for viral replication, particularly in macrophages.

While IL-34 promotes virus survival, it can also strengthen antiviral immunity. IL-34 levels were found to correlate negatively with genome copy number of hepatitis B virus (HBV) in vitro, suggesting that IL-34 could suppress HBV replication. Similarly, serum IL-34 levels were correlated inversely with HBV DNA levels in patients with chronic HBV infection [88]. Therefore, IL-34 seems to be a helpful clinical marker to evaluate HBV infection.

More recently, it has been demonstrated that IL-34 is involved in infections of fungus, parasite, bacteria, candidemia, and sepsis [89-91]. For example, $\mathrm{Xu}$ et al. [32] noticed that IL-34 down-regulated Candida albicans-induced TNF-a release from M1-type macrophages by suppressing Dectin-1 and TLR2 signaling, in turn maintaining immune tolerance in the skin and mucosa. These results support a novel role for IL-34 in the development of infections, although its impact is probably context-dependent and can vary depending on the infectious agent, the site of infection, and the phase of the infectious process.

\section{IL-34 in inflammatory disorders}

IL-34 plays an essential role in inflammatory disorders both in animal models and patients, including inflammatory bowel disease (IBD), skin disease, heart failure, chronic apical periodontitis, and type II diabetes mellitus. IBD is an inflammatory and autoimmune disease that includes ulcerative colitis and Crohn's disease. CSF-1R and PTP- $\zeta$ have been detected in intestinal epithelial cells as well as in monocytes and macrophages in the gut. Clinically, overexpression of IL-34 has been noted in the inflamed colon [92]. In the development of IBD, IL-34 amplifies the inflammatory cascade in the gut. It enhances the production of chemokines (e.g., CCL20) and pro-inflammatory cytokines (e.g., TNF-a, IL-6) via the ERK pathway [93]. In a recent study of ulcerative colitis in animal models, IL-34 induced Th2-type response and activated inflammatory remodeling, which was required for epithelial hyperplasia and fibrosis [94]. Therefore, IL-34 may be interesting as a novel marker to monitor IBD severity, and as a potential therapeutic target for treatment of the inflamed gut. In addition to the significance of IL-34 in the pathophysiology of IBD, it is now clear thatIL-34 is down-regulated in atopic dermatitis, which is characterized by inflammatory lesions, oozing papules, and plaques [95]. IL-34 can dampen the inflammatory cascade, thereby attenuating the active skin lesions.

Macrophage-based immune and inflammatory responses are involved in the pathogenesis of acute kidney injury (AKI). Macrophages can mediate kidney destruction or repair, thus playing dual roles in the fate of the kidney. CSF-1 contributes to the recovery of AKI via a macrophage-dependent mechanism: in a mouse model of ischemia-reperfusion induced AKI, expressions of IL-34, CSF-1R, and PTP- $\zeta$ are up-regulated in tubular epithelial cells. Local IL-34-induced macrophages augment the destruction of tubular epithelial cells and worsen AKI, while circulating IL-34 enhances the proliferation of myeloid cells and increases monocytes, thereby amplifying persistent inflammation [95]. In the clinic, high IL-34 levels are associated with severe AKI and subsequent chronic kidney disease [96]. Elevated levels of IL-34 are also found in patients who suffered kidney rejection after transplantation. In the engrafted kidney, IL-34 produced by tubular epithelial cells might trigger the expansion of $\mathrm{Ly} 6 \mathrm{G}^{+}$neutrophils and $\mathrm{CD}^{+} 8^{+}$macrophages [97].

In addition, IL-34-mediated inflammatory and immune responses are implicated in the pathogenesis of obesity-associated complications, heart failure, and chronic apical periodontitis [98-103]. For instance, adipocyte-derived IL-34 recruits macrophages to adipose tissues, leading to chronic inflammation and insulin resistance in type II diabetes mellitus $[102,103]$. IL-34 may act as a potential predictor of prognosis and severity in these diseases.

\section{Conclusions and perspectives}

Despite its recent discovery, IL-34 has already been identified as a multifunctional cytokine that regulates a variety of cellular processes including adhesion, differentiation, proliferation, metabolism, angiogenesis, inflammation, and immune responses. Notably, IL-34 plays a crucial role in the functions and survival of microglia and Langerhans cells. As the second ligand of CSF-1R, IL-34 efficiently promotes the differentiation, migration, and proliferation of monocytes/macrophages, which are involved in various pathophysiological states. At the same time, IL-34 participates in several signaling pathways that do not involve CSF-1. Syndecan-1 and PTP- $\zeta$ are alternative receptors of IL-34. The interactions between IL-34 and syndecan-1 influence cellular migration, modulate the activation of IL-34/CSF-1 binding, and inhibit glioma cell function. Precise mechanisms and additional receptors/regulators that interact with IL-34 need to be investigated in the 
future work.

Recently, there is increasing evidence that IL-34 affects different immune cells and participates in immune and inflammatory responses, thereby influencing the onset and progression of various diseases (Figure 4). Depending on the pathological conditions, increased formation of IL-34 amplifies inflammatory cascades or, conversely, mediates immune tolerance. Therefore, IL-34 shows promise as a prognostic biomarker in many diseases, including autoimmune diseases, cancer, transplant rejection, infections, and inflammatory diseases.

IL-34 may be useful as a therapeutic target in the management of illnesses. Treatment with IL-34 can prevent various diseases such as neurological disorders, skin lesions, transplant rejection, and infections. IL-34 provides powerful neuroprotection through its effect on microglia, neurons, and endothelial cells. It can induce the differentiation of pluripotent stem cells into microglia, suggesting a potential role in neural regeneration. Likewise, IL-34 is effective in mediating immune tolerance and ameliorating inflammatory lesions by inducing the expansion of Tregs and M2-polarized macrophages. IL-34-mediated tolerance also helps the control of inflammation in skin diseases and prolongs survival of the implanted grafts. Studies on the significance of IL-34 in outcomes of kidney and liver transplantation have been limited to animal models. Further works are warranted to investigate whether IL-34 can benefit other types of organ transplantation, and to elucidate the underlying mechanisms in details. In addition, IL-34 can suppress HBV replication and improve bacterial clearance, indicating that this cytokine may be useful as an adjuvant treatment for preventing HBV and bacterial infections. Interestingly, IL-34 exerts paradoxical effects on different viral infections. In contrast to the case of HBV infection, neutralizing IL-34 can inhibit HIV replication, as well as decrease profibrotic macrophages in the setting of $\mathrm{HCV}$ infection.

In the process of cancer, IL-34 induces immune tolerance and triggers pro-survival signaling. Therefore, blockade of IL-34 seems to be a potential approach for the treatment of several IL-34-producing cancers, as a strategy that is currently being investigated. Beyond cancer, the inhibition of IL-34 activity may help to alleviate inflammatory response by down-regulating the expression of pro-inflammatory cytokines. In this context, targeting IL-34 is expected to be a potential therapeutic strategy in the treatment of IBD, RA, and AKI.

In summary, the immunoregulatory properties of IL-34 appear to be of significance in a wide range of diseases. Elucidating the favorable and unfavorable effects of IL-34 in the immune microenvironment may be of great importance for a comprehensive understanding of its pathophysiological implication. Therefore, future research concerning the evaluation of therapeutic potential of IL-34 in human diseases are required.

\section{Abbreviations}

AKI: acute kidney injury; AMPK: AMP-activated protein kinase; CD: Crohn's disease; CSF-1: colonystimulating factor-1; CSF-1R: colony-stimulating factor-1 receptor; ERK1/2: extracellular signalregulated protein kinases 1 and 2; FAK: focal adhesion kinase; HBV: hepatitis B virus; HCV: hepatitis C virus; HIV: human immunodeficiency virus; IBD: inflammatory bowel disease; IL-34: interleukin-34; JAK: Janus kinase; JNK: c-Jun N-terminal kinase; MAPK: mitogen-activated protein kinases; p38 MAPK: p38 mitogen-activated protein kinase; NF-KB: nuclear factor of kappa B; PAMP: pathogen-associated molecular pattern; PI3K:

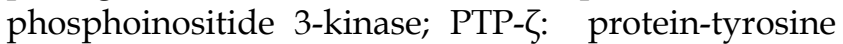
phosphatase $\zeta$; RA: rheumatoid arthritis; SLE: systemic lupus erythematosus; STAT3: signal transducer and activator of transcription 3; TAMs: tumor-associated macrophages; TGF- $\beta$ : transforming growth factor- $\beta$; Th: helper T cells; TLR: Toll-like receptor; TNF- $\alpha$ : tumor necrosis factor- $\alpha$; Tregs: regulatory T cells; ULK1: UNC-51-like kinase 1; UC: ulcerative colitis.

\section{Acknowledgements}

This work was supported by grants from the National Natural Science Foundation of China (81873 946, 81730057, 81842025), the Key Project of Military Medical Innovation Program of Chinese PLA (No. 18CXZ026), and the National Key Research and Development Program of China (2017YFC1103302).

\section{Author Contribution Statement}

YG and $\mathrm{MH}$ conducted the literature review and drafted the manuscript. Y-MY conceptualized and supervised the project, and revised the manuscript. All authors read and approved the final manuscript.

\section{Competing Interests}

The authors have declared that no competing interest exists.

\section{References}

1. Lin H, Lee E, Hestir K, Leo C, Huang M, Bosch E, et al. Discovery of a cytokine and its receptor by functional screening of the extracellular proteome. Science. 2008; 320: 807-811.

2. Dai XM, Ryan GR, Hapel AJ, Dominguez MG, Russell RG, Kapp S, et al. Targeted disruption of the mouse colony-stimulating factor 1 receptor gene results in osteopetrosis, mononuclear phagocyte deficiency, increased primitive progenitor cell frequencies, and reproductive defects. Blood. 2002; 99: $111-120$. 
3. Chow V, Brown BD, Merad M. Studying the mononuclear phagocyte system in the molecular age. Nat Rev Immunol. 2011; 11: 788-798.

4. Stanley ER, Chitu V. CSF-1 receptor signaling in myeloid cells. Cold Spring Harb Perspect Biol. 2014; 6: a021857.

5. Wei S, Nandi S, Chitu V, Yeung YG, Yu W, Huang M, et al. Functional overlap but differential expression of CSF-1 and IL-34 in their CSF-1 receptor-mediated regulation of myeloid cells. J Leukoc Biol. 2010; 88: 495-505.

6. Nakamichi Y, Mizoguchi T, Arai A, Kobayashi Y, Sato M, Penninger JM, et al. Spleen serves as a reservoir of osteoclast precursors through vitamin D-induced IL-34 expression in osteopetrotic op/op mice. Proc Natl Acad Sci USA. 2012; 109: 10006-10011.

7. Wang Y, Szretter KJ, Vermi W, Gilfillan S, Rossini C, Cella M, et al. IL-34 is a tissue-restricted ligand of CSF1R required for the development of Langerhans cells and microglia. Nat Immunol. 2012; 13: 753-760.

8. Greter M, Lelios I, Pelczar P, Hoeffel G, Price J, Leboeuf M, et al. Stroma-derived interleukin-34 controls the development and maintenance of Langerhans cells and the maintenance of microglia. Immunity. 2012; 37: 1050-1060.

9. Eda H, Shimada H, Beidler DR, Monahan JB. Proinflammatory cytokines, IL-1 $\beta$ and TNF- $\alpha$, induce expression of interleukin-34 mRNA via JNK- and p44/42 MAPK-NF-kB pathway but not p38 pathway in osteoblasts. Rheumatol Int. 2011; 31: 1525-1530.

10. Yu Y, Yang D, Qiu L, Okamura H, Guo J, Haneji T. Tumor necrosis factor- $\alpha$ induces interleukin-34 expression through nuclear factor- $\mathrm{KB}$ activation in MC3T3-E1 osteoblastic cells. Mol Med Rep. 2014; 10: 1371-1376.

11. Bézie S, Picarda E, Ossart J, Tesson L, Usal C, Renaudin K, et al. IL-34 is a Treg-specific cytokine and mediates transplant tolerance. J Clin Invest. 2015; 125: 3952-3964.

12. Nandi S, Cioce M, Yeung YG, Nieves E, Tesfa L, Lin H, et al. Receptor-type protein-tyrosine phosphatase $\zeta$ is a functional receptor for interleukin-34. J Biol Chem. 2013; 288: 21972-21986.

13. Segaliny AI, Brion R, Mortier E, Maillasson M, Cherel M, Jacques $\mathrm{Y}$, et al. Syndecan-1 regulates the biological activities of interleukin-34. Biochim Biophys Acta. 2015; 1853: 1010-1021.

14. Ma X, Lin WY, Chen Y, Stawicki S, Mukhyala K, Wu Y, et al. Structural basis for the dual recognition of helical cytokines IL-34 and CSF-1 by CSF-1R. Structure. 2012; 20: 676-687.

15. Felix J, De Munck S, Verstraete K, Meuris L, Callewaert N, Elegheert J, et al. Structure and assembly mechanism of the signaling complex mediated by human CSF-1. Structure. 2015; 23: 1621-1631.

16. Chihara T, Suzu S, Hassan R, Chutiwitoonchai N, Hiyoshi M, Motoyoshi K, et al. IL-34 and M-CSF share the receptor Fms but are not identical in biological activity and signal activation. Cell Death Differ. 2010; 17: 1917-1927.

17. Zhou J, Sun X, Zhang J, Yang Y, Chen D, Cao J. IL-34 regulates IL-6 and IL-8 production in human lung fibroblasts via MAPK, PI3K-Akt, JAK and NF-KB signaling pathways. Int Immunopharmacol. 2018; 61: 119-125.

18. Liu H, Leo C, Chen X, Wong BR, Williams LT, Lin H, et al. The mechanism of shared but distinct CSF-1R signaling by the non-homologous cytokines IL-34 and CSF-1. Biochim Biophys Acta. 2012; 1824: 938-945.

19. Boulakirba S, Pfeifer A, Mhaidly R, Obba S, Goulard M, Schmitt T, et al. IL-34 and CSF-1 display an equivalent macrophage differentiation ability but a different polarization potential. Sci Rep. 2018; 8: 256.

20. Zelante T, Ricciardi-Castagnoli P. The yin-yang nature of CSF1R-binding cytokines. Nat Immunol. 2012; 13: 717-719.

21. Guillonneau C, Bézie S, Anegon I. Immunoregulatory properties of the cytokine IL-34. Cell Mol Life Sci. 2017; 74: 2569-2586.

22. Baghdadi M, Endo H, Tanaka Y, Wada H, Seino KI. Interleukin 34, from pathogenesis to clinical applications. Cytokine. 2017; 99: 139-147.

23. Felix J, Elegheert J, Gutsche I, Shkumatov AV, When Y, Bracke N, et al. Human IL-34 and CSF-1 establish structurally similar extracellular assemblies with their common hematopoietic receptor. Structure. 2013; 21: 528-539.

24. Nakamichi $Y$, Udagawa N, Takahashi N. IL-34 and CSF-1: similarities and differences. J Bone Miner Metab.2013; 31: 486-495.

25. Wang $\mathrm{Y}$, Colonna M. Interkeukin-34, a cytokine crucial for the differentiation and maintenance of tissue resident macrophages and Langerhans cells. Eur I Immunol. 2014; 44: 1575-1581.

26. Garceau V, Balic A, Garcia-Morales C, Sauter KA, McGrew MJ, Smith J, et al. The development and maintenance of the mononuclear phagocyte system of the chick is controlled by signals from the macrophage colony-stimulating factor receptor. BMC Biol. 2015; 13: 12 .

27. NandiS, Gokhan S, Dai XM, Wei S, Enikolopov G, Lin H, et al. The CSF-1 receptor ligands IL-34 and CSF-1 exhibit distinct developmental brain expression patterns and regulate neural progenitor cell maintenance and maturation. Dev Biol. 2012; 367: 100-113.

28. Masteller EL, Wong BR. Targeting IL-34 in chronic inflammation. Drug Discov Today. 2014; 19: 1212-1216.

29. Wang Y, Bugatti M, Ulland TK, Vermi W, Gilfillan S, Colonna M. Nonredundant roles of keratinocyte-derived IL-34 and neutrophil-derived CSF1 in Langerhans cell renewal in the steady state and during inflammation. Eur J Immunol. 2016; 46: 552-559.

30. Lindau R, Mehta RB, Lash GE, Papapavlous G, Boij R, Berg G, et al. Interleukin-34 is present at the fetal-maternal interface and induces immunoregulatory macrophages of a decidual phenotype in vitro. Human Reprod. 2018; 33: 588-599.
31. Foucher ED, Blanchard S, Preisser L, Descamps $\mathrm{P}$, Ifrash $\mathrm{N}$, Delneste $\mathrm{Y}$, et al. IL-34- and M-CSF-induced macrophages switch memory T cells into Th17 cells via membrane IL-1 $\beta$. Eur J Immunol. 2015; 45: 1092-1102.

32. Xu R, Sun HF, Williams DW, Jones AV, A-Hussaini A, Song B, et al. IL-34 suppresses Candida albicans induced TNF-a production in M1 macrophages by downregulating expression of Dectin-1 and TLR2. J Immunol Res. 2015; 2015: 328146.

33. Raggi C, Correnti M, Sica A, Andersen JB, Cardinale V, Alvaro D, et al. Cholangiocarcinoma stem-like subset shapes tumor-initiating niche by educating associated macrophages. J Hepatol. 2017; 66: 102-115.

34. Baghdadi M, Wada H, Nakanishi S, Abe H, Han N, Putra WE, et al. Chemotherapy-induced IL34 enhances immunosuppression by tumor-associated macrophages and mediates survival of chemoresistant lung cancer cells. Cancer Res. 2016; 76: 6030-6042.

35. Foucher ED, Blanchard S, Preisser L, Garo E, Ifrash N, Guardiola P, et al. IL-34 induces the differentiation of human monocytes into immunosuppressive macrophages, antagonistic effects of GM-CSF and IFN-ү. PLoS One. 2013; 8: e56045.

36. Boström EA, Lundberg P. The newly discovered cytokine IL-34 is expressed in gingival fibroblasts, shows enhanced expression by pro-inflammatory cytokines, and stimulates osteoclast differentiation. PLoS One. 2013; 8: e81665.

37. Clavel G, Thiolat A, Boissier MC. Interleukin newcomers creating new numbers in rheumatology: IL-34 to IL-38. Joint Bone Spine. 2013; 80: 449-453.

38. Tian Y, Shen H, Xia L, Lu J. Elevated serum and synovial fluid levels of interleukin-34 in rheumatoid arthritis: possible association with disease progression via interleukin-17 production. J Interferon Cytokine Res. 2013; 33: 398-401.

39. Wang B, Ma Z, Wang M, Sun X, Tang Y, Li M, et al. IL-34 upregulated Th17 production through increased IL-6 expression by rheumatoid fibroblast-like synoviocytes. Mediators Inflamm. 2017; 2017: 1567120.

40. Wang B, Tang Y, Sun X, Ouyang X, Li H, Wei J, et al. Increased IL-6 expression on THP-1 by IL-34 stimulation up-regulated rheumatoid arthritis Th17 cells. Clin Rheumatol. 2018; 37: 127-137.

41. Baud'huin $M$, Renault $R$, Charrier $C$, Riet A, Moreau A, Brion $R$, et al. Interleukin-34 is expressed by giant cell tumours of bone and plays a key role in RANKL-induced osteoclastogenesis. J Pathol. 2010; 221: 77-86.

42. Chemel M, LeGoff B, Brion R, Cozic C, Berreur M, Amiaud J, et al. Interleukin 34 expression is associated with synovitis severity in rheumatoid arthritis patients. Ann Rheum Dis. 2012; 71: 150-154.

43. Hwang SJ, Choi B, Kang SS, Chang JH, Kim YG, Chung YH, et al. Interleukin-34 produced by human fibroblast-like synovial cells in rheumatoid arthritis supports osteoclastogenesis. Arthritis Res Ther. 2012; 14: R14.

44. Moon SJ, Hong YS, Ju JH, Kwok SK, Park SH, Min JK. Increased levels of interleukin 34 in serum and synovial fluid are associated with rheumatoid factor and anticycliccitrullinated peptide antibody titers in patients with rheumatoid arthritis. J Rheumatol. 2013; 40: 1842-1849.

45. Chang SH, Choi BY, Choi J, Yoo JJ, Ha YJ, Cho HJ, et al. Baseline serum interleukin-34 levels independently predict radiographic progression in patients with rheumatoid arthritis. Rheumatol Int. 2015; 35: 71-79.

46. Garcia S, Hartkamp LM, Malvar-Fernandez B, van Es I, Lin H, Wong J, et al. Colony-stimulating factor (CSF) 1 receptor blockade reduces inflammation in human and murine models of rheumatoid arthritis. Arthritis Res Ther. 2016; 18 : 75 .

47. Yang S, Jiang S, Wang Y, Tu S, Wang Z, Chen Z. Interleukin 34 upregulation contributes to the increment of MicroRNA 21 expression through STAT3 activation associated with disease activity in rheumatoid arthritis. J Rheumatol. 2016; 43: 1312-1319.

48. Zhou RP, Wu XS, Xie $\mathrm{YY}$, Dai BB, Hu W, Ge JF, et al. Functions of interleukin-34 and its emerging association with rheumatoid arthritis. Immunology. 2016; 149: 362-373.

49. Chemel M, Brion R, Segaliny AI, Lamora A, Charrier C, Brulin B, et al. Bone morphogenetic protein 2 and transforming growth factor $\beta 1$ inhibit the expression of the proinflammatory cytokine IL-34 in rheumatoid arthritis synovial fibroblasts. Am J Pathol. 2017; 187: 156-162.

50. Ding R, Li P, Song D, Zhang X, Bi L. Predictors of response to TNFantagonist therapy in Chinese rheumatoid arthritis. Clin Rheumatol. 2015; 34: 1203-1210.

51. Zhang F, Ding R, Li P, Ma C, Song D, Wang X, et al. Interleukin-34 in rheumatoid arthritis: potential role in clinical therapy. Int J Clin Exp Med. 2015; 8: 7809-7815.

52. Bethunaickan R, Berthier CC, Zhang W, Kretzler M, Davidson A. Comparative transcriptional profiling of 3 murine models of SLE nephritis reveals both unique and shared regulatory networks. PLoS One. 2013; 8: e77489.

53. Wang H, Cao J, Lai X. Serum interleukin-34 levels are elevated in patients with systemic lupus erythematosus. Molecules. 2016; 22: E35.

54. Xie HH, Shen $\mathrm{H}$, Zhang L, Cui MY, Xia LP, Lu J. Elevated serum interleukin-34 level in patients with systemic lupus erythematosus is associated with disease activity. Sci Rep. 2018; 8: 3462

55. Ciccia F, Alessandro R, Rodolico V, Guggino G, Raimondo S, Guarnotta C, et al. IL-34 is overexpressed in the inflamed salivary glands of patients with Sjogren's syndrome and is associated with the local expansion of pro-inflammatory CD14 (bright) CD16 ${ }^{+}$monocytes. Rheumatology. 2013; 52: 1009-1017. 
56. Baghdadi $\mathrm{M}$, Ishikawa $\mathrm{K}$, Endo $\mathrm{H}$, Umeyama $\mathrm{Y}$, Ataka $\mathrm{T}$, Wada $\mathrm{H}$, et al. Enhanced expression of IL-34 in an inflammatory cyst of the submandibular gland: a case report. Inflamm Regen. 2018; 38: 12.

57. Li J, Liu L, Rui W, Li X, Xuan D, Zheng S, et al. New interleukins in psoriasis and psoriatic arthritis patients: the possible roles of interleukin-33 to interleukin-38 in disease activities and bone erosions. Dermatology. 2017; 233: $37-46$

58. Noy R, Pollard JW. Tumor-associated macrophages: from mechanisms to therapy. Immunity. 2017; 41: 49-61

59. Cannarile MA, Weisser $M$, Jacob W, Jegg AM, Ries $\mathrm{CH}$, Ruittinger D. Colony-stimulating factor 1 receptor (CSF1R) inhibitors in cancer therapy. I Immunother Cancer. 2017; 5: 53.

60. Peyraud F, Cousin S, Italiano A. CSF-1R inhibitor development: current clinical status. Curr Oncol Rep. 2017; 19: 70.

61. Kumari A, Silakari O, Singh RK. Recent advances in colony stimulating factor-1 receptor/c-FMS as an emerging target for various therapeutic implications. Biomed Pharmacother. 2018; 103: 662-679.

62. Cioce M, Canino C, Goparaju C,Yang H, Carbone M, Pass HI. Autocrine CSF-1R signaling drives mesothelioma chemoresistance via AKT activation. Cell Death Dis. 2014; 5: e1167.

63. Booker BE, Clark RS, Pellom ST, Adunyah SE. Interleukin-34 induces monocytic-like differentiation in leukemia cell lines. Int J Biochem Mol Biol. 2015; 6: 1-16

64. Rietkotter E, Bleckmann A, Bayerlová M, Menck K, Chuang HN, Wenske B, et al. Anti-CSF-1 treatment is effective to prevent carcinoma invasion induced by monocyte-derived cells but scarcely by microglia. Oncotarget. 2015; 6: 15482-15493.

65. Ségaliny AI, Mohamadi A, Dizier B, Lokajczyk A, Brion R, Lanel R, et al. Interleukin-34 promotes tumor progression and metastatic process in osteosarcoma through induction of angiogenesis and macrophage recruitment. Int J Cancer. 2015; 137: 73-85.

66. Wang B, Xu W, Tan M, Xiao Y, Yang H, Xia TS. Integrative genomic analyses of a novel cytokine, interleukin-34 and its potential role in cancer prediction. Int J Mol Med. 2015; 35: 92-102.

67. Franzè E, Dinallo V, Rizzo A, Giovangiulio MD, Bevivino G, Stolfi C, et al. Interleukin-34 sustains pro-tumorigenic signals in colon cancer tissue. Oncotarget. 2017; 9: 3432-3445.

68. Baghdadi M, Endo H, Takano A, Ishikawa K, Kameda Y, Wada H, et al. High co-expression of IL-34 and M-CSF correlates with tumor progression and poor survival in lung cancers. Sci Rep. 2018; 8: 418

69. Han N, Baghdadi M, Ishikawa K, Endo H, Kobayashi T, Wada H, et al. Enhanced IL-34 expression in Nivolumab-resistant metastatic melanoma. Inflamm Regen. 2018; 38: 3.

70. Chen T, Wang X, Guo L, Wu M, Duan Z, Lv J, et al. Embryonic stem cells promoting macrophage survival and function are crucial for teratoma development. Front Immunol. 2014; 5: 71.

71. Zhou SL, Hu ZQ, Zhou ZJ, Dai Z, Wang Z, Cao Y, et al. miR-28-5p-IL-34-macrophage feedback loop modulates hepatocellular carcinoma metastasis. Hepatology. 2016; 63: 1560-1575.

72. Zhao Z, Pan G, Tang C, Li Z, Zheng D, Wei X, et al. IL-34 inhibits acute rejection of rat liver transplantation by inducing Kupffer cell M2 polarization. Transplantation. 2018; 102: e265-e274.

73. San Segundo D, Ruiz P, Irure J, Arias-Loste MT, Cuadrado A, Puente A, et al. Serum levels of interleukin-34 during acute rejection in liver transplantation. Transplant Proc. 2016; 48: 2977-2979.

74. Mizuno T, Doi Y, Mizoguchi H, Jin S, Noda M, Sonobe Y, et al. Interleukin-34 selectively enhances the neuroprotective effects of microglia to attenuate oligomeric amyloid- $\beta$ neurotoxicity. Am J Pathol. 2011; 179: 2016-2027.

75. Gómez-Nicola D, Fransen NL, Suzzi S, Perry VH. Regulation of microglial proliferation during chronic neurodegeneration. J Neuro Sci. 2013; 33: 2481-2493.

76. Luo J, Elwood F, Britschgi M, Villeda S, Zhang H, Ding Z, et al. Colony-stimulating factor 1 receptor (CSF1R) signaling in injured neurons facilitates protection and survival. J Exp Med. 2013; 210: 157-172.

77. Chitu V, Gokhan S, Nandi S, Mehler MF, Stanley ER. Emerging roles for CSF-1 receptor and its ligands in the nervous system. Trends Neurosci. 2016; 39: 378-393.

78. Ma D, Doi Y, Jin S, Li E, Sonobe Y, Takeuchi H, et al. TGF- $\beta$ induced by interleukin-34-stimulated microglia regulates microglial proliferation and attenuates oligomeric amyloid- $\beta$ neurotoxicity. Neurosci Lett. 2012; 529: 86-91.

79. Walker DG, Tang TM, Lue LF. Studies on colony stimulating factor receptor-1 and ligands colony stimulating factor-1 and interleukin-34 in Alzheimer's disease brains and human microglia. Front Aging Neurosci. 2017; 9: 244.

80. Jin S, Sonobe $\mathrm{Y}$, Kawanokuchi J, Horiuchi H, Cheng Y, Wang Y, et al. Interleukin-34 restores blood-brain barrier integrity by upregulating tight junction proteins in endothelial cells. PLoS One. 2014; 9: e115981.

81. Wang YQ, Cao WJ, Gao YF, Ye J, Zou GZ. Serum interleukin-34 level can be an indicator of liver fibrosis in patients with chronic hepatitis B virus infection. World J Gastroenterol. 2018; 24: 1312-1320.

82. Preisser L, Miot C, Le Guillou-Guillemette H, Beaumont E, Foucher ED, Garo E, et al. IL-34 and macrophage colony-stimulating factor are overexpressed in hepatitis $\mathrm{C}$ virus fibrosis and induce profibrotic macrophages that promote collagen synthesis by hepatic stellate cells. Hepatology. 2014; 60: 1879-1890.
83. Yu G, Bing Y, Zhu S, Li W, Xia L, Li Y, et al. Activation of the interleukin-34 inflammatory pathway in response to influenza A virus infection. Am J Med Sci. 2015; 349: 145-150.

84. Covaleda L, Fuller FJ, Payne SL. EIAVS2 enhances pro-inflammatory cytokine and chemokine response in infected macrophages. Virology. 2010; 397: 217-223.

85. Vasek MJ, Garber C, Dorsey D, Durrant DM, Bollman B, Soung A, et al. A complement-microglial axis drives synapse loss during virus-induced memory impairment. Nature. 2016; 534: 538-543.

86. Gerngross L, Fischer T. Evidence for cFMS signaling in HIV production by brain macrophages and microglia. J Neurovirol. 2015; 21: 249-256.

87. Gerngross L, Lehmicke G, Belkadi A, Fischer T. Role for cFMS in maintaining alternative macrophage polarization in SIV infection: implications for HIV neuropathogenesis. J Neuroinflamm. 2015; 12: 58.

88. Cheng ST, Tang H, Ren JH, Chen X, Huang AL, Chen J. Interleukin-34 inhibits hepatitis B virus replication in vitro and in vivo. PLoS One. 2017; 12: $\mathrm{e} 0179605$.

89. Mo ZQ, Li YW, Zhou L, Li AX, Luo XC, Dan XM. Grouper (Epinepheluscoioides) IL-34/MCSF2 and MCSFR1/MCSFR2 were involved in mononuclear phagocytes activation against Cryptocaryonirritans infection. Fish Shellfish Immunol. 2015; 43: 142-149.

90. Wang L, Jiang $\mathrm{L}, \mathrm{Wu} \mathrm{C}$, Lou B. Molecular characterization and expression analysis of large yellow croaker (Larimichthyscrocea) interleukin-12A, 16 and 34 after poly I: C and Vibrio anguillarum challenge. Fish Shellfish Immunol. 2018; 74: 84-93.

91. Lin X, Luo H, Yan X, Song Z, Gao X, Xia Y, et al. Interleukin-34 ameliorates survival and bacterial clearance in polymicrobial sepsis. Crit Care Med. 2018; 46: e584-e590.

92. Franzè E, Monteleone I, Cupi ML, Mancia P, Caprioli F, Marafini I, et al. Interleukin-34 sustains inflammatory pathways in the gut. Clin Sci. 2015; 129: 271-280.

93. Zwicker S, Martinez GL, Bosma M, Gerling M, Clark R, Majster M, et al. Interleukin 34: a new modulator of human and experimental inflammatory bowel disease. Clin Sci. 2015; 129: 281-290.

94. Jodeleit H, Palamides P, Beigel F, Mueller T, Wolf E, Siebeck M, et al. Design and validation of a disease network of inflammatory processes in the NSG-UC mouse model. I Transl Med. 2017; 15: 265.

95. Esaki H, Ewald DA, Ungar B, Rozenblit M, Zheng X, Xu H, et al. Identification of novel immune and barrier genes in atopic dermatitis by means of laser capture microdissection. J Allergy Clin Immunol. 2015; 135: 153-163.

96. Menke J, Iwata Y, Rabacal WA, Basu R, Yeung YG, Humphreys BD, et al. Menke CSF-1 signals directly to renal tubular epithelial cells to mediate repair in mice. J Clin Invest. 2009; 119: 2330-2342.

97. Baek JH, Zeng R, Weinmann-Menke J, Valerius MT, Wada Y, Ajay AK, et al. IL-34 mediates acute kidney injury and worsens subsequent chronic kidney disease. J Clin Invest. 2015; 125: 3198-3214.

98. Li Z, Jin D, Wu Y, Zhang K, Hu P, Cao X, et al. Increased serum interleukin-34 in patients with coronary artery disease. J Int Med Res. 2012; 40: 1866-1870.

99. Fan Q, Yan X, Zhang H, Lu L, Q. Zhang Q, Wang F, et al. IL-34 is associated with the presence and severity of renal dysfunction and coronary artery disease in patients with heart failure. Sci Rep. 2016; 6: 39324

100. Ma N, Qu L, Xu LY, Yu YQ, Qiu LH. Expression of IL-34 in chronic periapical lesions and its clinical significance. Shanghai Kou Qiang Yi Xue. 2016; 25: 53-57.

101. Tao R, Fan Q, Zhang H, Xie H, Lu L, Gu G, et al. Prognostic significance of interleukin-34 (IL-34) in patients with chronic heart failure with or without renal insufficiency. J Am Heart Assoc. 2017; 6: e004911.

102. Below JE Gamazon ER, Morrison JV, Konkashbaev A, Pluzhnikov A, McKeigue PM, et al. Genome-wide association and meta-analysis in populations from Starr County, Texas, and Mexico City identify type 2 diabetes susceptibility loci and enrichment for expression quantitative trait loci in top signals. Diabetologia. 2011; 54: 2047-2055.

103. Zorena K, Jachimowicz-Duda O, Waz P. The cut-off value for interleukin 34 as an additional potential inflammatory biomarker for the prediction of the risk of diabetic complications. Biomarkers. 2016; 21: 276-282. 